\title{
El Ejército Popular de Liberación y la Revolución Cultural
}

JOHN GITTIN (is es profesor investigador de asuntos de Asia en el Instituto dt: Estudios Internacionales de la Universidad de Cluile. Sus principales publicaciones incluyen: The Role of the Chinesc Army, Oxford University Press, 1967. La versión castellana apareceri este año bajo el sello de la Comisión Cenual de Publicatciones de la Universidad de Chile. Actualmente se encuentra en Fong-kong, escribiendo un libro sobre la política cxterior de chinat.

La Revolución Cultural en Cihina ha proclucido innumerables preguntals sin respuestas; tal ve las más provocativas y enigmáticas sean las que se relieren al papel que correspondió al Ejército Popular de Liberación dentro de este cataclismo político ${ }^{1}$. Por un laclo, se reyeló que una "gran lucha" interna existió en el Ejército Popular de Liberación, clurante cuyo curso el particlo desenmascaró a "representantes de la burguesín que habian usurpaclo importantes posiciones. clentro del ejército", y quienes" vanamente intentaron "sustituir una linea militar burguesa en lugar de la línea proletaria clel Presidente Mao Tse-tung" "." El lícler cle estal facción fue más tarcle iclentificado como Lo Jui-chi'ing, Jefe del Estado Mayor clel Epr. clesde 1959 y hasta entonces consideraclo como alguien sin tacha alguna política. Lo fue calificato ahora de revisionista contrarrevolucionario en alianza con el anterior Ministro de Defensa P'eng Teh-huai, quien había vendido bienes revisionistas importaclos descle una potencia extranjera, $y$, ạdemás, había plancado uma conspiración para usurpar la jefatura del EPL. Tambićn se observaron indicios de discordias en niveles inferiores de jefatura del EPL de proporciones muchísimo más graves que en ningún otro momento después del Gran Salto Adelante. En la Fuerza Aérea, la Armada, el Departamento de Servicios de Retaguar= dia y otros sectores claves del EPL se argumentó en contra del control

${ }^{1}$ Este artículo es una versión corregida y aumentada de mi artículo "The Chinese Army's Roic in the Cultural Revolution", publicado en Pacific Affairs vol. xxxr., N.os 3 y 4 , otoño c invierno 1966-67, pp. 269-89. Agradezco al director de Paci/ic Affairs su autorización para utilizarlo aquí.

"Chieh-fang-chün Pao (Periódico Ejërcito Libcración), (de aqué en adelante citado como CPCP), editorial, agosto 19, 1966, en Peking Review, agosto 5, 1966. 
del partido y del "pensamiento militar burgués". Al aumentar la intensidad de la Revolución Cultụral, algunos líderes provinciales y militares aparentemente ignoraron las instrucciones de la jefatura maoísta de Pekín, cuando no se opusieron activamente a ellas. Una especie de punto culminante se alcanzó a fines de julio de 1967, durante el famoso incidente de Wuhan; cuando el comandante de la Región Militar de Wulan abiertamente desafió, y supuestamente trató de secuestrar, a los propios representantes personales de Mao. Todos estos síntomas de descontento dentro del EPI. -si se tomasen al pie de la letra- fácilmente podrian llevarnos a la conclusión de que el ejér-. cito, lejos de ser leal al partido y a Mao, podría convertirse en unia poderosa fuerza de oposición política.

Sin embargo, una tendencia tolalmente opuesta a la anterior era también visible en la relación del EPL con la Revolución Cultural. Hubo una exaltación pública del Ministro de Defensa Lin Piao en el verano de 1966 a una posición infer:or solamente a la de Mao mismo en la jefatura del partido. Fue Lin y nadie más el considerado como "íntimo camarada cle armas" de Mao (una información de la agencia noticiosa Nueva China fue apresuradamente quitala ; corregida cuando describió a Lin apenas como un "camalada"). Fue Lin quicn señaló la pauta en la campaña para estudiar cl pensamiento de Mao ("Estudio de Mao") y quien pronunció los cliscursos principales durante las reuniones en masa de los Guardias Rojọs. Unicamente Lin fue descrito como el hombre que "resueltanente ha estado siempre firme al lado del Presidente Mao" durante todia la revolución china. Cuando Mao hizo su aparición en una asamblea de Guardias Rojos vistiendo el uniforme completo del kers, verde oliva con gorma estreIlada en rojo, el periódico del ejército no tardó en deducir la moraleja obvia: la presencia de Mao fue "el más grande honor para nuestro ejército e indica su enorme confianza e inspiración en nosotros....". Muy luego se comunicó que Mao había publicado un "gran llamado" al pueblo chino para que "aprendiese del Ejército Popular de Liberación de China". Para recalcar este punto, por primera vez. en muchos años, el desfile del Día Nacional en Pekín en 1966 fue principalmente militar o paramilitar y Lin Piao pronunció el cliscurso central. La elevación del EPL de esta manera podría en consecuencia llevarnos a una conclusión totalmente diferente: que el ejército bajo Lin Piao, si no exactamente "apoderándose" de una posición dominante, como algunas interpretaciones más exageradas lo han sugerido, por lo menos estaba en proceso de constituirse en el mayor aliado de Mao en la Revoluciōn Cultural. Esta impresión podriá plausiblemente apoyarse en el aparente control dèl ejército sobre los Guardias Rojos, en sụ 
Intervención física en la Revolución Cultural en algunas zonas desde enero de 1967 y en su frecuente arrogación del poder administrativo y político en sectores donde la autoridad centralizada del partido había siclo quebrantada.

Estas dos conclusiones tan divergentes expresan, aunque en forma exagerada, algo de verdad. Ya que la exaltación del EpL como un modelo político y la reaparición del descontento entre sus filas, lejos de ser fenómenos mutuamente incompatibles, son caras de una misma monecla. En rcaliclad, el primero tiende a suscitar el segundo. La Rerolución cultural sencillamente ha intensificado y dramatizado las contraclicciones latentes entre control del partido y comando militar -cntre prioriclacles políticas y prioridades militares- que han sido la mactcristica del ers. descle fines de la guerra en Corea.

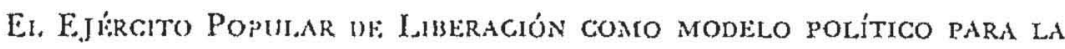
RFiolugión CULTURAL

A través cle la mayor parte cle la Revolución Cultural el EPL ha desempeñaclo un papel al cual ya estaba acostumbrado en los años precedentes, el cle ser marcador del paso político. Tras la destitución de P'eng Teh-huili en 1959, la renovación del control político sobre el EPL clurantc los años 1960-1963 proporcionó un modelo que ulteriormente lué seguiclo por la campaña de educación socialista iniciada en toda la nación. Similarmente, los rasgos característicos de la Revolución Cultumal de 1966 -elevación clel "Estudio de Mao" a niveles sin precedcntes, el implacable énfasis en la lucha de clases y' en la primacia de. lis política- fueron anticipados clentro del EPL descle fines cle 1964, culminanclo a meclida que la Revolución Cultural misma se ponia en marcha.

Durante cl otoño de 1960 , un año después del reemplazo de P'eng Tch-huai por Lin Piao, el Comité de Asuntos Militares del partido acometió una importante y prolongada campaña "para fortalecer cl tirabajo político e ideológico en el ejército", esto es, intensificar el control del partido y aumentar el conocimiento político en etnivel de la tropa. La forma asumida por esta campaña fue sagaz y sutil, demostrando una conciencia realista de los errores cometidos por el particlo en sus tratos con el EPL, especialmente en momentos del Gran Salto Adelante. La estructura de control político habría de ser revisada y revivificada cabalmente, hasta el nivel mismo de compañía, acentuando tanto la educación como el control. Pero, al mismo tiempo, el EPL fue cada vez menos a menudo llamado a participar en ac- 
tividades externas ajenas a su función (labor productiva, campañas econónicas, etc.), y"otras medidas semejantes fueron tomadas para restablecer la moral militar. La campaña nacional "Aprende del EPL" de 1964 indicó que estas medidas terapéuticas habían logrado bastante éxito y que el EPL era considerado a la sazón como un modelo digno de ser emulado en cualquier campo de la sociedad.

Era específicamente la experiencia del EPL en "educación política y trabajo ideológico" el ejemplo que la nación debia seguir. Las, técnicas del EPL para el control y educación -las "cuatro-primeras" relaciones, los "cuatro-bienes" y "cinco-bienes" y otros movimientos similares- servirían ahora para ser copiadas en la vida civil. Talleres y departamentos en la industria y comercio fueron igualmente instruidos para que estableciesen sus propias secciones del partido basadas directamente en una analogía con la sección del partido existente en cada compañía del EPL. Cuadros militares y oficiales fuera de servicio activo fueron a menudo reclutados para trabajar en la organización de estas secciones.

Desde 1964, el EPL ha continuado su actuación como ejemplo político. Héroes tipos, ya sea individualmente o en forma colectiva, han sido destacados como brillantes ejemplos del ejército para que sirvan de lección al resto de la sociedad. Pérsonifican éstos aquellas cualidades que la jefatura desearía inculcar en las generaciones futuras de quienes dependerá el destino del socialismo: abnegación, amor por el pueblo, resolución revolucionaria sin temor a la muerte e incondicional aceptación del pensamiento de Mao Tse-tung.

En diciembre de 1964, Lin Piao dictó un mandato llamando al EPL a "dar prominencia a la política de acuerdo con las enseñanzas de Mao". Este fue seguido por "un nuevo surgimiento del estudio flexible y aplicación de los escritos del Presidente Mao...."3. Úna escuela política del ejército en Changsha fue presentada como un modelo para ser emulado por "todas las escuelas del Partido... y todas las universidades y escuelas secundarias", por la forma en que, con todo éxito, había "supeditado el pensamiento educacional burgués al" pensamiento educacional proletario" $₫$. En mayo el sistema jerárquico y de graduación del EPL, introducido diez años antes en época que se realizaba una modernización militar, fue abolido en favor cle la "democracia militar".

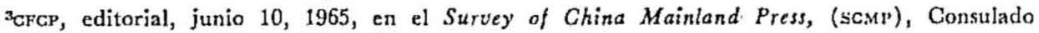
General de uss, Hong-Kong, No 3.487.

'Diario del Pueblo, editorial, marzo 19, 1965, en nBc Summary of World Broadcasts, The Far East, (FE), 1807. 
Era más bien el maoísmo antes que la educación política en general lo que se indicaba con la frase "dar prominencia a la política". Las obras de Mao habrían de ser estudiadas "en todo trabajo y toda actividad". La mayoría de los miembros del ejército estaban instruidos para "estudiarlas regularmente a diario"5. Esto no se limitó a la tropa ni a los suboficiales; el estudio del maoísmo fue descrito como "particularmente importante para los cuadros de jefes en todos los niveles, especialmente los de alto nivel", para asi asegurar que el EPL permanecería "por siempre invencible y sin degeneración"в. En noviembre 15, 1965, Lin Piao publicó instrucciones de trabajo para el EPL durante 1966. Una orden de "considerar las obras del Presidente Mao Tse-tung como las más altas instrucciones sobre todos los aspectos clel trabajo de todo nuestro ejército" encabezaba la lista. Este tema fue discutido más a. fondo en el editorial del periódico del ejército del Día de Año Nuevo, el que elogió el pensamiento de Mao en el lenguaje que se tornaría en la característica de la Revolución Cultural ${ }^{7}$.

El estudio de Mao, se explicaba, era antes que nada un instrumento de la lucha de clases, un medio de garantizar que "sucesores revolucionarios" pudiesen ser adiestrados para perpetuar las gloriosas tradiciones del EPL. Consistía en "un gran diseño para construir nuestro ejército en los próximos cien, mil y diez mil años", una manéra de "mantener los rifles en manos de personas dignas de confianza"s. La búsqueda de sucesores revolucionarios fue llevada a la práctica en las filas del EPL. Profusión de nuevos cuadros formados por micmbros de origen obrero o campesino pobre fueron destinados a "posiciones cle jefatura"; cientos de miles de soldados jóvenes ingresaron al Partido Comunista e igualmente grandes cantidades se unieron a la Alianza de Juventudes Comunistas.

Así fue como la totalidad del conterrido ideológico de la Revolución Cultural se elaboró y llevó a la práctica dentro de las filas del EPL. El papel marcador del paso del EPL en esta empresa ha sido abiertamente reconocido. El Diario del Pueblo en su editorial de julio 19, 1966, afirmó claramente que "el EPL inició el movimiento hacia el estudio creativo y aplicación de las obras del Presidente Mao". Una declaración proveniente del Departamento Político del EpL explica por qué el ejército hubo de ser elegido para desempeñar este papel.

"CFCP, editorial, marzo 17, 1965, en $\mathrm{YE}, 1819$.

ACFCP, editorial, julio 14, 1965, en scmp 3511.

-En scmp 3619, "Las palabras del Presidente Mao son palabras desde el más alto nivel, de la más alta autoridad y con el mayor poder. Son verdaderas hasta su última palabra. La fuerza de cada una de sus palabras equivale a la de diez mil palabras de otro".

Iscimp 3511 . 
Dado que el EPL es "un ejército proletario personalmente creado por el Presidente Mao", y. en vista de que se encuentra bajo la directa jefatura de la central del partido, del Presidente Mao y de Lin Piao, tiene en consecuencia "la obligación así como las condiciones favorables para aprender un poco mejor que otros de las obras del Presidente Mao, a fin de colmar las esperanzas del Partido y de todo nuestro pueblo"'.

El EPL continuó marcando el paso cuando lo Revolución Cultural misma se puso en marcha. La revolución escaló clesde sus orígenes relativamente modestos como un movimiento de rectificación de los asi llamados intelectuales burgueses, dirigido primeramente contra Wu Han y otros individuos asociados con el comité del particlo en Pekín. Aunque innumerables ataques habian sido lanzados contra intelectuales chinos prominentes desde 1964, fue el ataque a $W u$ Han, vicealcalde de Pekín e historiador, en noviembre de 1965, el que desató la sucesión de acontecimientos que culminaron con la destitución del secretario del partido de Pekín, P'eng Chen, del Ministro de Cultura Lu Ting-yi y otras autoridacles prominentes y terminaron con el surgimiento de los Guardias Rojos. La primera salva de artillería que inició el ataque fue lanzada clescle un artículo del teórico Yao Wen-yuan en el Wen-yi Pao de Shanghai ic noviembre 10. Tras cierta dilación durante la cual aparentemente el partido de Pekín intentó impedir que el asunto fuese más lejos, el periódico del ejército Chieh-fang-chün Pao reimprimió el artículo de Yao el 29 de noviembre. El Diario del Pueblo, arrastrando sus pies, siguió el ejemplo un día más tarde. Desde entonces hasta la purificación del particlo de Pekín (incluyendo al Diario del Pueblo) en junio de 1966, cualquier movimiento de importancia de la campaña de prensa iniciado en contra de Wu Han y otros fue siempre comenzado del mismo modo; primeramente por el periódico del ejército, y la prensa civil siempre a la zaga.

Ya en junio de 1966, por lo menos con algunos de los "demonios y monstruos" de la "banda antipartido" de P'eng Chen derrotados en la confusión, el escenario se encontraba listo para la glorificación última de Mao, la que, en menos de dos meses, llevó los hechos al surgimiento de los Guardias Rojos. Esta nueva fase fue iniciada con la publicación sumultánea, en todos los periódicos principales, de una carta escrita con anterioridad por Lin Piao a todos los departamentos nacionales industriales y de comunicaciones. El pensamiento de Mao, escribía Lin Piao, "ha resumido las nuevas experiencias del movi"

'Resumido en New China News Agency (NaNA), mayo 4, 1966, (scmp 3698). 
miento internacional comunista $y$ ha elevado al marxismo-leninismo a una etapa absolutamente sin precedentes"10.

\section{Aumenta la disensión dentro del EPL, 1965-66}

En el verano y otoño de 1966, por consiguiente, el EPL aparentemente navegaba sobre la cresta de una ola de popularidad e influencia política. Sin embargo, esta era solamente la mitad de la historia, la otra mitad fuc la reaparición del descontento entre sus propias filas. No es en absoluto accidental que este fenómeno haya coinciclido con la dramática intensificación clel sistema de "la política en comando" de los años 1965-66. Existe un paralelo aquí con los años 1957-58, cuando los cada ve\% más fuertes intentos del partido para politizar al exr. y para comprometerlo en gran escala dentro, de la producción $y$ otros trabajos de masas, probaron ser totalmente contraproducentes. El resultado neto de estos intentos fue la generación del desafecto que precisamente buscaban evitar. La linea divisoria entre lo aceptable y lo inaceptable en materia de intervención del partido clentro del EPs, parece ser muy clelgada; aparentemente, una vez más fue cruzada en algún momento clel año 1965.

Esto no significa que la discordia dentro del EPL alcanzase ahora proporciones indominables, ni que el concepto básico del control del partido fuese ampliamente puesto en duda. La gran mayoría de los oficiales del EPL y una gran proporción de la tropa son miembros del partido. Este hecho, unido a la solidez de las tradiciones revolucionarias del EPL, se combinan para lograr que las fuerzas armadas sean uno de los elementos más estables clentro de la sociedad china actual. Sin embargo, parece ser más bien el grado antes que el principio de control partidario y trabajo político lo que comenzó a causar desaliento entre algunos oficiales profesionales. Ellos expresaron su opinión, por ejemplo, de que "las armas y la política son igualmente importantes", y que debieran ser "puestas en primer plano por turnos", en vez de permitir que la política siempre dominase. Otra variante de este punto de vista sostenía que al destacar tanto la política "igualmente habrían de lograrse los resultados, que son -en la verdad de las cosasel tiro al blanco y lanzamiento de granadas de mano"11. Los servicios de armas especializadas (por ejemplo, Fuerza Aérea y Arma da) al parecer estaban especialmente preocupados por el modo en que, desde 1965, las excesivas actividades políticas habían empezado a interferir con el entrenamiento mismo. Varias conferencias se realizaron en el verano de 1966 para aclarar estos problemas. Durante

10peking Review, junio 24, 1966.

${ }^{11} \mathrm{CFCP}$, editorial, febrero 18, 1966, en scmp 3644. 
una conferencia de la Fuerza Aérea algunos participantes se quejaron de que, desde la iniciación de la Revolución Gultural, "hemos concentrado toda nuestra atención en la educación política y apenas mantenido el adiestramiento militar". Mordazmente se advirtió que ". . . la Fuerza Aérea lucha en el aire y difícilmente puede llamarse una fuerza aérea si acaso los pilotos no saben volar..."12. La opinión oficial era que el adiestramiento militar era inútil, salvo que estuviese fuertemente subordinado al trabajo político. También era creencia oficial que en 1964-65 se había dado un énfasis excesivo al entrenamiento militar y que era llegado ahora el momento de compensar el equilibrio. El hecho de que el adiestramiento aduciclo pudiese haber producido excelentes resultados se consideraba fuera cle lugar.

Debemos analizar frases tales como "resultados excelentes" y "buenos resultados" para encontrar las ideas [tras aquéllas] y ser cómo los indlividuos obtuvieron sus resultados en trabajo y adliestramiento, cómo se lits manejaron con su trabajo, con las dificultacles, lo colectivo, los logros y honores, y si acaso todia estal actividad concordós con lats enseñanzas del Presidente Mao o no13.

Nada puede ilustrar más claramente el abismo existente entre la vía profesional y la vía política que esta cita. Concluye opinando que incluso si aquellos "resultados excelentes" en rerdad concuerdan con las enseñanzas de Mao, este hecho sigue siendo de importancia secundaria comparado con la lucha cle clases. No es nada sorprendente que la Fuerza Aérea en particular, con la perspectiva de una mayor escaladia de la guerra de Vietnam siempre presente en sus mentes, haya puesto obstáculos a la campaña pro estudio cle Maio. En una conferencia de octubre de 1966, el comisario político de la Fuerza Aérea reveló que "comparada con sus unidades fraternales, el movimiento de estudio dentro de la Fuerza Aérea está aún sumamente atrasado" y que se encontraba "muy, muy por debajo" cle la pauta exigicla por Lin Piao y el Comité de Asuntos Militares del Particlo't.

Un segundo motivo del desacuerdo interno del EpL puede haber sido el intento aparente de revivificar algunas de las prácticas "revoluicionarias" menos populares que labian sido suspendidas después del Gran Salto Adelante. La Milicia Popular, respecto a la cual el EPL siempre tuvo sentimientos encontraclos, había sido nuevamente

\footnotetext{
${ }^{12}$ cFep, mayo 17, 1966, información sobre una discusión dentro de cierta unidad de la Fucrza Acrea, ell scmp 3706.

${ }^{13}$ NCNA, junio 13, 1966, información sobre una discusión dentro de cierta división del cjército ḋe Pekin, en scmp 3724.

${ }^{1}$ Radio Pekin, octubre 21, 1966, informa sobre una rcunión de la Fuerza Aérca en octubre 20, 1966, en FE 2301.
} 
aumentada, a pesar del poco éxito del anterior intento de 1958-1960. En marzo de 1966 se dice que la milicia constaba de alrededor de 100 millones de hombres y mujeres, casi la mitad del total del Gran Salto y tres veces más que los cálculos más recientes. Un informe de Hsu Li-ch'ing, subdirector del Departamento de Política General, sugería que las autoridades del particlo locales debieran ser alentadas a fortalecer su control sobre la milicia a expensas de las autoridades del EPL ${ }^{15}$. También se insistió nuevamente en la necesidad de que çuadros de oficiales del ejército clebieran descender a las filas para experimentar las condiciones de vicla de un soldado raso en forma directa. Esta práctica también habia siclo popular durante el Gran Salto y más tarde tácitamente fue abandonada. Pero después que Mao urgió a algunos cuadros de lícleres, durante una asamblea de Guardias Rojos, a "ir a las masas", el periódico del ejército señaló que los oficiales de todos los niveles, especialmente aquellos pertenecientes a niveles de ejército, divisiones y regimientos, clebian "adelantarse e ingresar en las compañias y uniclacles primarias"16. Una institución de Mao Tsetung, publicada muy poco antes del Día del Ejército 1966, pareció igualmente renovar el concepto de participación masiva del, EPL en la labor cle producción agrícola e industrial. Esta había sido üna práctica llevada hasta excesos durante el Gran. Salto y la oposición ante esta medida, según se cree, había siclo una de las causas de la caída de P'eng Telh-huai. En 1958 el EPL había contribuido supuestamente con 59. millones de "jornadas-hombre" al trabajo cle producción; en 1963 esta cifra había descendido a $81 \% 2$ millones, e incluso menos en 1964-65.' La instrucción de Mao ahora ordenaba que:

El Epí debiera ser una gran escuela. En csta gran cscucla, nuestros militares debieran aprender sobre politica, asuntos militares y cultura. También pueden ocuparse en la producción agrícola y trabajos adicionales, manejar algunas fábricas medianas o pequeñas... También pueden efectuar trabajos en masa y tomar partc en él movimiento cle educación socialista dentro de las fábricas y aldeas ${ }^{1 \bar{t}}$.

${ }^{25}$ Nav York Times, abril 13, 1966; Guardian, abril 15, 1966. Hsu también dijo que las unidades de la milicia debían servir de puente entre el cjército y las masas. Podian esparcis la experiencia y métodos del f.ru. a las masas $y$ también informar al EPt. sobre el pensamiento y forma de trabajar de los habitantes locales.

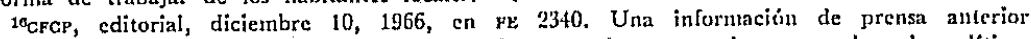
dice que "para lograr captar las ideas vitales de los cocheros... algunos cuadros de políticos se mudaron a los establos.... Asi pudicron cmbarrarse tanto como los mismos cocheros". Yang-ch'eng Wan-pao, junio 19, 1966, en scMp 3715.

${ }^{17} \mathrm{La}$ orden de Mao fue citada en el editorial del periódico militar en el Día del Ejército (ver nota 2). Se había cuviado por medio de una carta de Mao a Lin Piao fechada el 7 de mayo, 1966, pero no. se publicó hasta el Día del Ejército, Radio Lhasa, mayo 1967 (FE $2470)$. 
$\mathrm{La}$ instrucción finalizaba con la estipulación de que "Cada unidad del ejército debe oçuparse en uno o dos de tres campos de actividad: agricultura, industria y trabajo en masa, pero no en los tres simultáneamente".

El clesacuerdo sobre la estrategia militar en vista de la guerra en Vietnam puede también haber contribuido al creciente descontento dentro del EPL. La Revolución Cultural representa una vuelta a las bases fundamentales de la doctrina de Mao; para el EPL, esto significa la subordinación de la estrategia militar a la doctrina de la guerra popular y la sustitución de la preparación militar por la ideológica. Es posible reconstruir una serie cle interrogantes que la escalada de la guerra en Vietnam en 1965 debe haber planteado $y$ las alternativas que estas mismas creaban. ¿Debería China intervenir en Vietnam mismo $y$, en tal caso, en qué momento? ¿Debería China tratar cle coordinar la ayuda a Vietnam con la Unión Soviética y otros países socialistas? ¿Cuál tipo de movilización y preparativos clefensivos deberían ejecutarse internamente contra la posibilidad de que la guerra finalmente escalara hasta el punto cle envolver a la China misma?

Las respuestas ortodoxas maístals ante estas interrogantes surgieron más o menos al mismo ticmpo que comenzó lat Revolución Cultural, durante el otoño e invierno de 1965. Las promesas de ayuda china al Vietnam, que en un principio habían sido relativamente explícitas $y$ firmes, comenzaron a ser menos frecuentes y más vagamente expresadas. Las alusiones amenazantes al precedente sentado por la guerra de Corea y las promesas de envíos de tropas a Victnam si eran solicitadas, no fueron nuevamente repetidas. La "acción conjunta" con la Unión Soviética fue definitivamente rechazadla durante una importante ráfaga cle propaganda desatada en noviembre de 1965 (aunque ya se habían expresado dudas sobre ésta desde la Reunión de Moscú de marzo del mismo año) ${ }^{18}$. La intransigencia china respecto a estos problemas muy pronto alcanzó tales dimensiones como para enajenarle dos de sus mejores aliados comunistas asiáticos: Corea del Norte y el Partido Comunista de Japón. Finalmente, se habló mucho menos de la movilización militar y preparación de China. En lo sucesivo, se hizo hincapié casi exclusivamente en la movilización ideológica por medio del Estudio de Mao. Se deduce una impresión general de que durante 1965-1966 hubo un vuelco hacia una posición más introvertida y chinocentrada en relación a la guerra en Vietnam. La guerra comienza a ser considerada cada vez menos en términos de su efecto sobre Vietnam

\footnotetext{
18Secciones editoriales del Diario del Pueblo y de Bandera Roja, "Refutación de los Nucvos Lideres del c.P.s.u. respecto a la Acción Conjunta", Peking Review, noviembre 12, 1965.
} 
$y$, en cambio, más como una posible amenaza a la seguridad interna de la propia China. Los medios de defensa elegidos son, muy naturalmente, la movilización ideológica en preparación a la guerra popular ${ }^{19}$.

La remoción del Jefe del Estado Mayor Lo Jui-ch'ing podría par- cialmente ser explicada por desacuerdos sobre la estrategia respecto a la guerra en Vietnam. Cabe hacer notar que sus dos proclamas principales durante 1965 destacaron la necesidad de una adecuada preparación militar y de un serio compromiso con el Vietnam, y prestaron relativamente muy poca atención a la doctrina de la "guerra popular", a la vez que censuraban superficialmente el revisionismo soviético ${ }^{20}$. Discrepancias respecto a estos puntos podrían también parcialmente explicar varias alusiones hechas. durante 1965 a "là línea militar revisionista", al "pensamiento militar burgués" y a aquellos miembros del EPL "cuyas cabezas están henchidas de doctrina extranjera"21.

Se podría suponer que la "gran lucha" que rodeó la destitución de Lo Jui-ch'ing había infligido un daño irreparable a la cohesión y soliclaridad estructural del F.PL. Sin embargo, la evidencia tiende a demostrar lo contrario, que el periódico del ejército -sin lugar a dudas por motivos propios -exageró la gravedad de esta "lucha" y que los rangos superiores de la jefatura del EPL no se vieron seriamente afectados por ésta. En el otoño de 1966 todos los otros miembros conocidos del Comité de Asuntos Militares del partido, fuera de Lo Jui-ch'ing, seguian muy evidentemente en sus puestos, así como los directores de los Departamentos Político $y^{\circ}$ de Servicios de Retaguardia ${ }^{22}$. Aparentemente, tampoco habia producido la Revolución Cultural hasta ese momento mayores cambios en el segundo escalón de la jefatura militar: los comandantes de regiones militares y de servicios especializados, o entre los subdirectores o subcomandantes del estado mayor en el Ciuartel General del EpL en Pekin. Si se toma una muestra de setenta miembros de este escalón para el período 1960-62, analizado en el capítulo anterior, se sabe que seis muriéron y que otros cuarenta y seis eran perfectamente visibles, en agosto-octubre de 1966, en posiciones de autoridad (por lo general la misma posición ocupada en $1960 \mathrm{o}$.

\footnotetext{
"Para mayor discusión de la relación existente entre la Revolución Cultural y la política china hacia Vietnam, ver John Gittings, "Will China Fight?", Far Eastern Economic Revietw, marzo 2, 1967; Franz Schurmann, "What Is Happening in Clina?", Nate York Reviezv of Books, octubre 20, 1966.

so"Conmemoremos la victoria sobre el fascismo alemán...", en Peking Reviezt, mayo 14, 1965; y "El pueblo derrotó al fascismo japonés y ciertamente puede derrotar al imperialismo de USA tambićn", en Peking Revietw, septiembre 3, 1965.

zVer Ho Lung, "Las tradiciones democráticas del zpt. Chino", Diario del Pueblo, agosto 10, 1965, en Peking Review, agosto 5, 1965.

"Liu Po-ch'eng, Ho Lung, Hsu Hsiang-ch'ien, Nieh Jung-chen, Yeh Chien-ying, Hsiao Hua y Ch'iu Hui-tso. Ch'iu habia sido ya sin embargo censurado en los murales.
} 
anteriormente). En esta muestra se incluyen siete de los ocho subcomandantes de estado mayor que estaban subordinados a Lo Jui-ch'ing y podrían, en consecuencia, haber sido envueltos en su caída. También están incluidos todos los comandantes de armas especializadas conocidos y la mayoría de sus comisarios políticos. Más de la mitad de los comandantes y comisarios políticos de las regiones militares también pudieron ser identificados durante este breve período, y los siete ministros a cargo de ministerios con especial importancia militar (Granjas del Estado, Petróleo, 40 al 89 Ministerios de Inclustria de Maquinaria) continuaban sin cambios.

Si acaso, entonces, efectivamente existió una "camarilla antipartido" dentro del EPL, bajo la jefatura de Lo, no hubo indicios de que sus miembros fuesen desenmascarados, como era dable esperar en el mismo año de la destitución de Lo. Se podría concluir, sin embargo, tras una lectura superficial de los cargos públicamente dirigidos en contra de Lo clurante el verano de 1967 y en las publicaciones de los Guardias Rojos, que en verdad existió dicha camarilla. Mas, debemos ser extremadamente cuidadosos antes de creer literalmente en estas acusaciones, o cualquier otra hecha clurante la Revolución Cultural. Las abrumadoras acusaciones que estos cargos contienen sugeririan un complot antimaoista de enormes dimensiones dirigido por Liu Shao-ch'i (cuyo supuesto agente dentro del EPL sería Lo Jui-ch'ing), pero las pruebas específicas aducidas en apoyo de Ios cargos son sorprendentemente débiles y carecen de credibilidad ${ }^{23}$.

Debemos tener presente que la posición del Jefe de Estado Mayor es particularmente vulnerable y aislada, características que comparte con las posiciones de alta jerarquía de los Directores Político y de Servicios de Retaguardia. Es a este nivel de jefatura que el conflicto entre las exigencias políticas de lo alto y las exigencias militares provenientes de las bases ha resultado ser más agudo, como lo indicaria el abandono de estos cargos por sus anteriores ocupantes durante los inciertos y revueltos años de 1958-1960. La destitución de Lo más bien sirve para destacar el porcentaje de mortalidad relativamente alto de este susceptible estrato del comando militar.

\section{EL PELIGROSO ACTO DE EQUILIBRIO DEL EPL, 1966}

En octubre de 1966, por tanto, durante el apogeo de la campaña de adulación del EPL y del Mariscal Lin Piao, el tejido del EPL aún no

23El problema de la credibilidad de los cargos lanzados contra Lo y otros lídéres del zPL, y de la medida en que deberá ser revisada nuestra evaluación original del papel polftico del EPL, se discute en la penúltima sección de cste artículo. 
aparentaba haber sido seriamente dañado por la Revolución Cultural. Se podría resumir la posición del EPL en términos de una ecuación simple: acreccntaclo prestigio político, por una parte, $y$, por la otra, una muy atumentada intervención política. Parece probable que la primera parte de esta ecuación hasta cierto punto compensó la segunda. Por mucho que las exigencias políticas irritasen a lọ cuadros de oficiales jóvenes del EPL, ellos no podían evitar reconocer el hecho que, descle 1960, bajo la jefatura de Lin Piao, el EPL había adquirido un grado cle prestigio popular nunca antes alcanzado salvo durante la guerra. Hay que reconocer que los problemas del adiestramiento no figuraban prominentemente en parte alguna de la ecuación. Quienes se preocupaban por la habiliclad del EPL para hacer frente a una mayor escalada cle la guerra en Vietnam u otras amenazas externas similares, no se sentirían consolaclos con el creciente prestigio interno del ejército. Pero es clucloso si hubo oposición muy difundida al respecto. Como ya hemos visto, es posible entrever esta actitud en el sensitivo nivel de planificación del Jefe del Estado Mayor (Lo Jui-ch'ing) y en aquellos servicios de amas especianizadas (por ejemplo, Fuerza Aérea) que vivían en constante alerta contra la invasión. Los comandantes cle estado mayor del EPL en las provincias limítrofes también pueden haberse alarmado, pero aquellos cle las provincias centrales con toda seguridad se ocupaban mạ́s de mantener la ley doméstica y el orden que de la posibilidad de una agresión desde el exterior.

Estudiando más de cerca esta misma ecuación, uno comienza a descubrir ciertas limitaciones por ambos lados que ayudaron a mantenerla en equilibrio. Primero, por muy impresionante que aparentara ser el recientemente adquirido prestigio político del EPL, era sorprendentemente difícil efectuar un análisis cuantitativo en modo significativo alguno. En realidad, existieron muy pocas pruebas de que el EPL hubiese, por lo menos a fines de 1966, adquirido poderes organizativos o políticos de naturaleza permanente o de dimensiones importantes. La Revolución Cultural no produjo una afluencia dramática de miembros del EPL hacia las más altas cumbres de la jefatura del partido. Solamente tres (Yeh Chien-ying, Nieh Jung-chen y tal vez Hsu Hsiang-ch'ien) parecen haber ingresado al Politburo, y sólo uno (Yeh Chien-ying) al Secretariado24. Durante los grandes cambios del liderato después de la expulsión de P'eng Chen, el EPL apenas figuró. Aunque tanto Li Hsueh-feng y T'ao Chu, reemplazantes de P'eng Chen como Primer Secretario en Pekín y de Lu Ting-yi como Director

2rYeh Chien-ying habia presuntamente tomado el lugar de Lo Jui-ch'ing en el Secretariado; Hsieh Fu-chih, Ministro de Seguridad Pública, también parecía haber ingresado al Politburo. 
del Departamento de Propaganda del Partido, respectivamente, habian tenido experiencia militar (la misma con que cuenta la mayoría de las altas autoridades del partido que pertenecen a la generación revolucionaria), se han especializado durante la década pasada más bien en asuntos del partido que militares. Solamente dos oficiales del EPL, ninguno muy conocido, fueron representantes del Comité de Revolución Cultural del Partido original ${ }^{25}$. El único nombramiento estrictamente militar fue ocupar el puesto concurrente de Lu Ting-yi como Ministro de Cultura por Hsiao Wang-t'ung como Ministro Interino de Cultura (Hsiao habla sido, sin embargo, subsecretario desde enero de 1965). En diciembre de 1966, cuando todos los arriba nombrados comprobaron su falta de fervor revolucionario y fueron reemplazados, sus sucesores, una vez más, no fueron miembros del EPL.

Los cambios de los jefes superiores parecen haber sido determinados por el compromiso con la Revolución Cultural como tal del ocupante del puesto y por sus antagonismos o lealtades personales hacia Mao mismo. Es imposible hallar un conflicto abierto entre el "ejército" y el "partido" (términos que en todo caso son tan inclusivos que comienzan a perder sentido práctico, especialmente desde la aparición en el partido de facciones pro y anti-Mao). Esta opinión no ignora que la autoridad del EPL fue invocada en su favor por Mao -especialmente durante las asambleas de Guardias Rojos en el verano y otoño de 1966- para proporcionar así un firme respaldo a su facción. Esta exhortación fue realizada casi ostentosamente, como si se quisiera anunciar a la oposición: "miren quiénes están a mi lado, guárdense de las consecuencias"'26. Sin embargo, fue esencialmente el mito carismático del EPL al que Mao recurrió, pero no, en esta etapa, a su poder. En la medida en que líderes del EPL adquirían influencia, esta influencia clerivaba principalmente del imprimatur de Mao y de la función marcadora del paso político por seguir asignada al EPL durante la RevoIución Cultural. Mao salió fuera del establishment del partido para buscar apoyo entre sus colegas militares íntimos, veteranos de sus años revolucionarios. No equivale este hecho a una entrega del poder al EPL. El fin perseguido por Mao con la Revolución Cultural es perpetuar en la sociedad china el mito revolucionario; mito cuya incorporación material es el EPL. El futuro del pueblo de China, no del EPL, es su preocupación fundamental.

2Liu Chib-chien y Hsia Chang-hou.

2Por ej., en la Asamblea de Guardias Rojos de agosto 31, 1966, cuando Mao llegó en un automóvil descubierto a ln Plaza Tien An Men acompañado por Lin Piao, Ho Lung, Hsieh Fu-chih y Yang Cheng-wu; precedidos por otro automóvil que les abría camino, lleno de oliciales menos importantes (información en el Peking Review, septiembre 9, 1966). 
Prasiguiendo con este argumento, convenía igualmente a los intereses tanto de la facción de. Mao cómo de la jefatura del ept que el EPL no se "apoderase del poder" en la práctica. A lo largo de 1966, el EPý le fue útil a Mao como una confirmación última potencial, tanto más impresionante al no ser utilizada. Nadie podía pronosticar con seguridad qué lado tomaría el EpL si era llamado a la acción; igualmente, nadie se atrevía a tomar el riesgo. Pero una vez que el apoyo fuese invọcado, las consecuencias podrían ser tan dañinas para Mao como para su oposición e incluso podian llevar a una situación en la cual solamente el EPL obtuviese provecho. Ni siquiera la jefatura del EPL demostró deseo alguno de ser llamada a la acción. Con seguridad estaba muy consciente de que su.unidad y control centralizado dependían en gran medida de la inactividad; una vez que los comandantes regionales y militares fuesen obligados a tomar partido, la estructura y cohesión interna del EPL arriesgaban ser la primera baja. .

Tal desgano ante la posibilidad de encontrarse implicados, fue al parecer abiertamente demostrado por Lin Piao en enero de 1967, cuando Mao finalmente llamó al EpL a la acción (ver más adelante). Se ha especulado muchísimo con los motivos personales de Lin Piao durante todo el transcurso de la Revolución Cultural. Observadores occidentales le han presentado a veces como el principal "halcón" y defensor de la guerra popular; a veces como el ambicioso pretendiente a la sucesión. La propaganda soviética ha especulado complacida sobre el tema de Lin Pia como eminencia gris tras el trono, sugiriendo incluso cierta vinculación ilicita entre Lin y Chiang Ching. (la esposa de Mao Tse-tung), siguienclo así la mejor tradición de las intrigas dinásticas de palacio. Estas interpretaciones se apoyan más bien en la especulación que en la evidencial. La defensa de Lin de la "guerra popular", notoria en su cliscurso de septiembre de 1965 sobre el tema, resulta ser únicimente una reposición ortodoxa de la posición maoísta, belicosa en su lenguaje, pero muy cauta en su programa. No implica una posición audaz ni agresividad en la política militar o externa. Al contrario, el discurso de Lin ha sido interpretado dentro del contexto de la guerra en Victnam como una advertencia a Hanoi y a la FLN para que no dependan de la ayuda externa ${ }^{27}$. Coincide en cambio con el vuelco hacia el interior dentro de la perspectiva mundial de China y con su falta de interés por iniciar una acción temeraria en Vietnam, como ya ha sido discutido anteriormente.

Durante una cle las primeras etapas de la guerra de Corea, Lin cedió el comando de los Voluntarios del Pueblo Chino a P'eng Teh-

DD. P. Mozingo \& T. W. Robinson, "Lin Piao on People's War: China Takes a Second Look at Vietnan", Santa Monica: Rand Corporation, 1965. 
huai. Mala salud y posiblemente falta cle simpatía hacia las tendencias


50 , mantuvieron a Lin fuera clel canipo político hasta 1958 , el año de su nombramiento como Min istro de Defensa para reemplazar a P'eng Telh-huai én 1959 (la'relaciön existente entre las carreras de P'eng y Lin sugiere algo mis que coinciclencia, pero este problema quedará aún $\sin$ investigar). Descle 1959, Lin ha asumiclo personalmente un estrecho control sobre el proceso de politización del EPL, publicando importantes instrucciones y enunciando fundamentales pronunciamientos teóricos, aunque sus apariciones en persona han siclo poco frecuentes, probablemente clebiclo as su prolongada mala salud: Como Ja se ha destacado, no existió una "toma del pocler" de alguna importancia en posiciones clel particlo por parte del ejército en estos años, como habría siclo daclo esperar si acaso Lin abrigaba ambiciones de suplantar el Iiderato del particlo. Por el contrario, desde 195860 un gran número de comisarías políticas de distritos $y^{\prime}$ regiones militares han sido ocupadas por la principal autoridad de partido inrolucradil (por lo genemal, el primer secretario del particlo, provincial o regional).

El papel cle Lin, en consecuencia, ha sido esencialmente una actuación cle vocero de la doctrina maósta 28 . Sin embargo, Lin, fuera de ser un leal maoísta, es sin lugar a cludas igualmente leal con los intereses del EPL - tal como él los considera - y no anhela que éstos se desorganicen debido a una excesiva intervención política; aunque su juicio respecto a lo que se consicleraría excesivo diferiría del juicio cle cualquier otro de sus colegas menos maoistas. No se puede tampoco climinar el elemento de habilísimo juicio táctico que contiene la defensa de Lin clel punto de vista de Maro descle 1960. Ya que el segundo niembro de la ecuación EPL - aumentada intervención política- tanto como el primero -incrementaclo prestigio político- contiene también ciertas limitaciones implícitas que han beneficiado al EPL; No sólo omitió la política post-1959 ciertas de las medidas revolucionarias más desagradables impuestas sobre el EPL en años anteriores, sino que aclemás el EPL ha sido inmune a los efectos más divisionarios de la Revolución Cultural. Encabezanclo la vanguardia del ataque de Mao a la oposición, el EPL evitó ser incluido dentro de esta última. Después de la caícla de P'eng Chen y sus partidarios, se vio claramente que otros

\footnotetext{
3iEs unuy posible que Mao, en su capacidad de presidente ex officio del Comité de Asuntos Militares del Partido, personalmente aprobase, si acaso no iniciasc, los detalles de la politización post-1960 del EPs. Amplianente, se podría decir que Mao "preparó" al epr. para su papel dentro de la Revolución Cultural, aunque esto no significa que Mao conscientemente plancara y anticijase la Revolución Cultural en la misma forma que ésta ha asunido.
} 
exponentes más destacaclos clel capitalismo burgués aún debian' ser" eliminados de la jefatura del partido. Pero cuando, al mismo tiempo; la "gran lucha" que llevó a la caída de Lo Jui-ch'ing fue revelada, se recalcó firmemente que la pugna dentro del ejército estába absolutamente concluida. No se permitió publicar ningún indicio que insinuase que aún restasscn otros elementos indeseables escondidos dentro' dél EPL. La inmuniclad clel EPL ante la Rerolución Cultural se declaró explícitamente por medio de la Decisión de 16 Puntos del Comité Central, en agosto S, 1966. Efectivamente, la transcripción del punto 15 es la siguiente:

Dentro de las fuerzas armadas, la revolución cultural y el movimiento de educación socialista deben ser ejecutados de acuerdo a las instrucciones de la Comisión Militar del Comité Central y del Departamento de Political General del Ejército de Liberación Popular'29.

En otras palabras, el EPL, único privilegiaclo entre todos los sectores de la sociedad china, no quedaba sujeto a la dirección del Grupo de Revolución Cultural del partido bajo Ch'en Po-ta y Chiang Ching.

Aunque es muy dilícil encontrar clocumentación, aumenta nuestra impresión de que las protestas de lealtad política del EPL han encubierto hasta cierto punto su falta de éxito en llevar a cabo algunas de las exigencias más extremadas que le fueran hechas. Las instrucciones de Mao respecto a la participación del IPL en la agricultura, industria o trabajos en masa no fueron notoriamente comentadas en la prensa china e incluso el movimiento "hacia las filas" cayó en la oscuridad. A pesar de la publicidard inicial, informes más recientes sobre la milicia no sugieren que valyan éstas a jugar un papel más que auxiliar, dando su mayor énfasis a la producción. Tal vez una falla de los niveles más bajos para pocler llevar a cabo los grandiosos planes iniciádos desde arriba explicaría las advertencias en contra de la "complacencia" y la "arrogancia" entre las filas del EPL; advertencias que constantemente se renuevan. $Y$ ', por lo demás, es muy posible que los altos niveles de jefatura clel EPL, aprovechando la gloria refleja de la elevación de Lin Piao a intima camaradería con Mao, se hayan tornado en com= placientes, seres poco inclinados a trasladar los esquemas desde el papel a la realidad.

EL EPL PIERdE SU EQUILIBRIO: INTERYENCIÓN Y CONFUSIÓN, 1967

Los meses desde cliciembre de 1966 hasta febrero de 1967 experimentaron una dramática intensificarión de la Revolución Cultural, al

orpeking Revietu, agosto 12, 1966. 
acelerarse ésta con el surgimiento de "rebeldes revolucionarios" proMao a través de todo el país. Estos grupos intentaron, con bastante éxito, arrancar el poder de manos de la burocracia regional del partido, cuya jefatura estaba claramente identificada con Liu Shao-ch'i y Teng Hsiao-p'ing. En retrospectiva, la fase de Guardias Rojos que precedió a esta nueva etapa se ve inconclusa y restringida. La Revolución Cultural fue ahora extendida a la industria y agricultura, sectores que, aparentemente por tácito acuerdo, hasta el momento se habían liberado. En esta etapa, varios líderes supuestamente pro-Mao cayeron en desgracia, presumiblemente porque se negaron a sancionar cualquier escalada mayor de la campaña. Entre éstos se incluyen T'ao Chu, Li Hsueh-feng y' varios otros oficiales superiores. Durante esta etapa se hizo evidente la naturaleza del peligroso acto de equilibrio ejecutado por el EPL en la Revolución Cultural; al mismo tiempo que síntomas de tensión puclieron ser descubiertos en su relación con la jefatura pro-Mao. Dos acontecimientos en particular clescompensaron el equilibrio de la ecuación clescrita más arriba: la reorganización del Grupo de Revolución Ciultural del EpL y el compromiso de éste de apoyar a los rebeldes revolucionarios; ambos hechos ocumieron en enero de 1967.

El 12 de enero se anunció que el Grupo Revólución Cultural del EPL había siclo reorganizado, para lograr así "fortalecer el liderato sobre la gran revolución cultural proletaria en toclo el ejército"30. Fuera de estos cambios en su composición, de alli en adelante quedaría sometido directamente a la jefatura del Comité de Asuntos Militares y del Grupo de Revolución Cultural del Partido. Así, el propio órgano político del EPL, el Departamento de Política General, habia sido juzgado inadecuado y sustituido por el órgano del partido (o más bien partido-Mao) como fuente de autoridad última. A esto siguieron editoriales en el periódico del ejército que, contrariando todas sus antiguas declaraciones, reconocieron la existencia continuada de "un pequeño grupo de personas con autoridad que toman el camino capitalista y una pequeñísima cantidad de intransigentes que se aferran a la línea burguesa reaccionaria" dentro del EpL. El periódico hizo un llamado al ejército para que abriese "feroz fuego" contra estos individuos y para que se esforzase en superar la marca alcanzada por la Revolución Cultural del EPL ${ }^{31}$.

Decididamente se había desarrollado en el seno del EPL, igual que en otros lugares, la oposición a la última intensificación de la Revolu-

${ }^{0} \mathrm{NCNA}$, enero 12, 1967, en TE 2364.

${ }^{{ }^{2}}$ CFCP, editoriales de enero 12 y 14, 1967, en re 2364 y 2366. 
ción Cultural. Aquellos atacados fueron acusados de reprimir el movimiento popular y de "alterar los blancos de ataque para su mejor protección". La resistencia a la Revolución Cultural también fue reconocida entre los cuadros de oficiales del ejército que habian tenido "una muy deficiente comprensión clel deber del líder en esta gran lucha", y los cuales eran aun "receptivos a lia línea burguesa reaccionaria". Lo esencial del asunto fue resumiclo por el reconocimiento de que "algunas personas son de opinión cle que no existe ningún problema importante dentro clel ejército y que no importa si acaso la gran revolución cultural llega alli o no".

La oposición clentro del EPI. que seguía estas líneas surgió aparentemente durante dicicmbre de 1966 . El 28 de noviembre Chiang Ching habia sido nombracla como "consejera" del Grupo de Revolución Cultural del EPro, primer síntoma de que faltase entusiasmo dentro del grupo. Una notoria declinación en la prominencia de Lin Piao taimbién ocurrió simultáneamente, $y^{\prime}$ puede ser significativo que su autoridacl no haya sido invocada en apoyo cle la reorganización del Grupo un mes más tarcle. En enero, varios lícleres prominentes del E:Pt cayeron por primera rez bajo cl ataque. Entre ellos sc incluían dos subdirectores del Departamento de Política Cieneral, quienes supuestamente habian siclo responsables de la rerolución cultural del EPL y algunos oficiales previamente asociados con T'ao Cliu en la Región Militar Central Sur². El Director Político, Hsialo Hua, también fue someticlo al ataque, aunque más tarde fué exoneraclo por Chou En-lai, de acuerdo a los informes. Pero lis victima mís dramítica fue el ex Mariscal Ho Lung, Vicepresidente del Comité de Asuntos Militares. Ho, según los informes, fue clescrito como un "hombre de origen banclolero", que habia "penetraclo en el ejército para hacer carrera". Otras acusaciones lo culpaban de haber tenido conexiones con los elementos "más reaccionarios" clel ejército, y especialmente con la jefatura de la Fuerza Aćrea y la Armada (cuyo Comandante Hsia Chingkuang también sulría el ataque) y cle haber, junto a ellos, pretendiclo derrocar a Lin Piao. El Levantamiento de Nanchang de agosto 19, 1927, que liasta ahora había sido celebrado como el Día del Ejército del ExL, en el cual Ho Lung había desempeñado un papel destacaclo, fue denunciado como una violación fundamental de la línea revolu-

s2Los subdirectores del Depto. Político cran Liang Pi-yeh y Liu Chih-chien. Liu, según sc inlormo, fue acusado de haber cnviado grupos de trabajo al ept para suprimir el movimiento de masas y de negarse a permitir el intercambio de experiencias revolucionarias entre los soldados. 
cionaria del Presidente $\mathrm{MaO}^{33}$. Es probable que Ho haya tenido reservas respecto a la Revolución Cultural ya en julio y que su oposición haya madurado hasta una definición a fines de año, cụando ésta debería ser extendida hasta las filas del EPL. Sus dudas pueden haber sido compartidas por Chu Teh, el glorioso viejo héroe del EPL y antiguo Comandante en Jefe (también acreditado por los historiadores comunistas de haber tenido un papel importante durante el Levantamiento de Nanchang), de quien se dijo que había incurrido en la ira de Mao al negarse a dar su apoyo a la Revolución Cultural ${ }^{34}$.

Hasta la tercera semana de enero, el EPL siguió una política de "no intervención" durante los intentos de los rebeldes revolucionarios para "conquistar el poder". Esta política que, es de presumir, reflejaba la opinión mayoritaria del comando del EPL, incluyendo a Lin Piao, fue invertida el 21 de enero por Mao en un mandato a Lin: "Es necesario enviar al ejército en ayuda de las masas de ala izquierda y revolucionarias. El ejército debe ayudar dondequiera existan genuinos revolucionarios y cada vez que ellos pidan tal ayuda. La así llamada no intervención es falsa no intervención. Hace mucho ya que se ha tornado en intervención. Respecto a esto, pido que una nueva orden sea publicada y que la anterior sea rescindida" ${ }^{35}$. Esta instrucción fue muy pronto obedecida por un periódico del ejército que llamó al EPL a "apoyar entusiastamente" a los rebeldes revolucionarios "sin la menor trepidación", aunque ellos sean temporalmente sólo una minoría"36.

Es probable que Mao haya deseado evitar la utilización del ejército, pero que se haya visto obligado a pedirle ayuda cuando las fuerzas de la oposición comprobaron tener más poder que el que era dable esperar. La gran mayoría de/ la burocracia del partido parece haber resistido a los rebeldes a través de una variedad de tácticas, que incluyeron la organización de huelgas, interrupción de la producción, con-

33"'El Levantamiento del 10 de agosto en Nanching violó fundamentalmente la línea revolucionaria del Presidente Mao. El ẹ́rcito sublevado batió banderas del KMr y sin embargo toda su acción se limitó a mantener la violencia armada en la ciudad en forma puramente militar. Intentó contar con ayuda internacional (signilicando: asesoría soviética) para apoderarse del poder en todo el pais". Radio Nanchang, febrero 5, 1967, información de la asamblea anti-Día del Ejército del EPL en Kiangsi, en pe 2386.

${ }^{3} \mathrm{De}$ acuerdo a una versión de actualidad en Pekín, Mao le pidió a Chu Teh que efectuase su autocrítica por no haber apoyado la Revolución Cultural, o que por lo menos escribiese artículos en la prensa a su favor. Chu no solamente se negó a esto sino que además contestó que si alguien debía realizar su autocrítica, esta persona scria Mao mismo. Radio. Tanyug, marzo 19, 1967, en FE 2406.

${ }^{3}$ Radios Tokio y Budapest. Citan cartel expuesto en las oficinas de Pekin del NCNA después de la autorización del Depto. Político del zpt, enero 23, 1957, én FR 2374. La csencia de estas instrucciones fue confirmada en un editorial del crcp "de enero 25.

${ }^{0} \mathrm{CPCP}$, editorial, enero 25, 1967. "E1 EPL Chino Firmemente Apoya a los Revolucionarios Proletarios!', en Fe 2375. 
quista de los sindicatos comerciales y autoridades menores por medio de beneficios en dinero, formación de grupos "rebeldes" rivales y el fomento de una dislocación social general para la cual, en todo caso, las condiciones estaban maduras. Es igualmente probable que la mayoria de la jefatura del EPL tuviera serias dudas sobre si era recomendable tomar partes. Los acontecimientos siguientes comprobaron que la invocación de la autoridad militar por Mao probó ser una notable arma de doble filo.

La extensión y naturaleza de la intervención militar hasta fines de febrero, cuando la Revolución Cultural tuvo un momento de calma, es extremadamente difícil de establecer. De acuerdo a un análisis, de once provincias donde los rebeldes revolucionarios dijeron haberse "tomado" o "apoderado" de las organizaciones del partido y del gobierno, solamente tres no se vincularon a la intervención del EPL. En otras nueve provincias, incluyendo Mongolia Interior, Sinkiang y Tibet, unidades del ejército hubieron de actuar en forma de emergen-cia, pero sin lograr expulsar a la oposición ${ }^{3 i}$. No fue siempre claro qué se entendía por intervención. En algunos casos, manifestaciones de campesinos y obreros fueron dispersadas por el ejército; en otros, instalaciones claves de comunicaciones y del gobierno fueron resguardadas por soldados; en otros lugares, reuniones revolucionarias fueron ostentosamente apoyadas por soldados con equipo militar completo. Tampoco fue siempre claro si acaso la totalidad del comando provincial autorizó a sus unidades para entrar en acción, o si acaso hubo un cisma entre las fuerzas provinciales mismas. En aquellos lugares donde no se dieron los nombres de los portavoces militares que apoyaban a los rebeldes o eran oficiales de poca importancia, como ocurrió frecuentemente, es razonable suponer que los altos jefes se opusieron o no quisieron verse comprometidos. En Sinkiang, Tibet y Mongolia, se informó sobre choques entre unidades del ejército, aunque el alcance de estos encuentros puede haber sido exagerado en los murales de los Guardias Rojos.

Este confuso cuadro sin duda refleja considerable desorientación dentro del EPL. mismo. Si hubiese intervenido decididamente, se podría haber esperado que las fuerzas promaoistas barriesen el pais durante febrero. Su fracaso en este sentido puede haber sido un factor tanimportante que haya determinado la tregua que se produjo más tarde (aunque los requerimientos económicos - la urgente necesidad de realizar el trabajo agrícola de primavera- fueron probablemente los factores decisivos). Se puede comprender el desgano de los comandan-

atThe Economist, marzo 4, 1967, pp. 809-810. 
tes locales del EPL ante la posibilidad de verse envueltos en la Revolución Cultural, y de comprometerse a dar su apoyo a una facción en particular que muy luego podría encontrarse en la oposición. La intervención del EPL parece que despertó igual hostilidad entre los revo. lucionarios de extrema izquierda como en toda la población. Según los promaoístas, estos sentimientos de rencor. han sido utilizados con mucho éxito por las burocracias locales del partido. En un'caso (Chinghai), aparentemente el EPL intervino por segunda vez para restituir a los revolucionarios que fuesen hostiles hacia la Revolución Cultural pero en otrós sentidos genuinamente pro-Mao. En Shansi, de acuerdo al Comisario Político del Distrito Militar, "elementos' capitalistas" del comité provincial del partido intentaron "forzarnos en su favor y trataron de usar el elevado prestigio del EPL para mixtificar a las masas y protegerse éllos mismos" 38 . Sin embargo, en otras regiones, se sostuvo que "malos elementos" "incitaron a las masas a difamar, cercar y atacar al EPL y a golpear a los comandantes y soldados del EPL". Nuevamente en Shansi, rebeldes revolucionarios superdogmáticos acusaron a los lideres militares que los apoyaban de ser "carteristas políticos", o sea, oportunistas.

Al empeorar la confúsión, la "triple alianza" entre rebelcles revolucionarios, cuadros de oficiales progresistas y el EpL fue oficialmente respaldada por Mao Tse-tung como la manera correcta de formar nuevas administraciones tras la "toma de posesión". Esto contuvo el extremado igualitarianismo y antiátoritarismo de algunos cle los rebeldes y garantizó cierta continuidad con la anterior administración, pero también aumentó el grado de participación del EPL en el gobierno local. Este hecho desató al 'parecer nuevamente el descontento. En un editorial de Bandera Roja, 9 de marzo, respecto a la "triple alianza", se hacía gran hincapié sobre el papel jugado por el kpL dentro de esta alianza. Se advertía que los enemigos clasistas estaban intentando todo lo posible para "esparcir rumores y fabricar hechos en un vano intento de sembrax la discordia entre las masas revolucionarias y el EPL y de instigar a las masas embaucadas para que dirigiesen la punta de lanza de su lucha contra el EPL". Pero más abajo se reconocía que "algunos camaradas locales" dentro del EPL "pueden momentáneamente cometer errores en su labor de apoyo" a los rebeldes revolucionarios. Estos últimos debian "explicar la situación a -sus camaradas militares responsables", pero no debían adoptar una actitud antagónica hacia el EPL $^{39}$.

28 Artículo de Chang Chih-ching en Bandera Roja, No 4, 1967, (Fr 2404).

${ }^{30}$ Bandera Roja, No 5, 1967, editorial "En torno a la triple alianza revolucionaria de tres vías", en PE 2413. 
Estas palabras implican que, en ciertos lugares, unidades del EPL habían intervenido con demasiado celo y tal vez no siempre en favor de los maoístas. Un editorial en el periódico del ejército, unos días más tarde, insinuaba precisamente lo opuesto: que aún existía resistericia a intervenir en absoluto. Este atacaba el concepto falso de "autointerés", causante de dicho desgano, y reafirmaba que la intervención del EPL genuinamente serviría al mejor "interés público" 40 . Algunos comandantes del EPL claramente opinaban lo contrario, ya fuese debido a su aversión o antipatía hacia la Revolución Cultural, o para así lograr proteger a sus unidades de la confusión reinante cada vez que se efectuaba tal compromiso.

Una víctima notable de la intervención del EPL en la.Revolución Cultural fue el concepto de "unidad ejército-pueblo", o sea de relaciónes armoniosas entre las fuerzas armadas y la población civil. Estas relaciones habian siclo por lo general buenas en el pasado, y la última oportunidad en que se hubiese reconociclo cualquier deterioro en ellas fue durante las campañas de rectificación de 1957-58. Pero los confusos sucesos de principios de 1967 parecen nuevamente haberlas tornado tirantes.

Durante el periodo inicial de la intervención militar en la Revolución Cultural, se recalcó la necesidad de que el pueblo aceptase la autoridad del ejércitó sin objeción alguna. El Comité de Asuntos Militares publicó para este efecto una ordenanza especial de ocho puntos el 28 de enero, una semana clespués que el EPL récibió la orden de intervenir. El 6 de abril, sin émbargo, el Comité publicó una ordenanza adicional de diez puntos recalcando justamente lo contrario: cómo debía el ejército "tratar correctamente con las masas". Esto fue revelado durante un discurso de Chiang Ching (esposa de Mao) el 20 de abril, en el curso del cual ella sostuvo que las dos ordenanzas eran complementarias y no contradictorias, lo que distaba mucho de ser la verdad ${ }^{+1}$. La dificultad yacía en la necesidad cle conciliar la deferencia hacia la autoriclad militar con el respeto por el espíritu de la democracia expresado, especialmente a nivel local, durante la Revolución Cultural. En oportunidades en que el EpL sí intervino, éste-a menudo se basó en su propio juicio para decidir cuál de los grupos en contienda debía ser considerado como genuinamente maoista y, por consiguiente, merecedor de recibir su apoyo. En otras ocasiones, puede

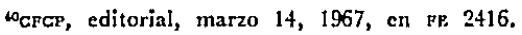

${ }^{1 L} \mathrm{La}$ orden da ocho puntos fue publicada en Kyodo, enero 10, 1967 (FE 2381). La orden de diez puntos fue comentada por Chiang Ching en un discurso de abril 20, 1967 (FE 2446); $y$ en el Diario del Pueblo, editorial, mayo 12, 1967 (Fq 2464). 
que deliberadamente haya intervenido a favor de la facción antimaoísta. En ambas situaciones se colocaba en posición sumamente expuesta a violentas críticas provenientes de los grupos no favorecidos. Chiang Ching aconsejó que "Quienquiera desee expresar su opinión respecto al ejército puede hacerlo libremente...; pero jamás deberá dirigir la punta de lanza de la lucha en contra del ejército". Subsistía aún la interrogante de cómo lograr hacer críticas al ejército sin "dirigir la punta de lanza de lucha en su contra".

Después de la publicación de la ordenanza de diez puntos, de acuerdo con una información, el EPL fue instruido de mantenerse fuera de la política y a limitarse al campo de la persuasión y propaganda. Pero la resultante pérdida de respeto hacia la autoridad del EPL provocó un difundido desorden social, hasta que nuevamente en junio el EPL obtuvo amplios poderes para entendérselas con la situación. Esta vez el EPL se mostró por lo general poco inclinado a intervenir sin instrucciones precisas y detalladas. En la única y clara ocasión en que así actuó, el incidente de Wuhan en julio, el comandante local se encontró apoyando al sector equivocado y antimaoísta. Este incidente "solamente reforzó la convicción de los comandantes del ejército de que era mejor mantenerse pasivos ante las contiendas políticas". La jefatura de Pekín entonces intentó restablecer su control sobre las unidades regionales similares a la que habia sido responsable del incidente de Wuhan, enfilando críticas hacia el Departamento de Política General del EPL y a los comisarios políticos regionales; además, trató de establecer nuevamente relaciones más estrechas y directas entre los rebeldes revolucionarios y los comandantes militares locales. El 25 de agosto, durante un intento de restaurar el prestigio del EPL y de mejorar sus relaciones populareś, Mao Tse-tung personalmente inició una campaña nacional para "Apoyar al ejército y amar al pueblo", en la cual ambas partes eran urgidas a trabajar en conjunto y olvidar sus diferencias ${ }^{42}$.

\section{LA COMPROBACIÓN DE LA OPOSICIÓN DEL EPL HACIA MAO, 1967}

La celebración del Día del Ejército del 19 de agosto de 1967 se efectuó bajo condiciones poco habituales. Sólo unos pocos días antes habja ocurrido el incidente de Wuhan; incidente que llevó a la destitución de Ch'én Tsai-tao, comandante de la Región Militar de Wuhan. En lugar de los habituales himnos de alabanza hacia el EPL, el Día del

42Este párralo se basa en la versión de Harold Munthe-Kaas, "Mao trics to reassure China's puzzled army", The Times (Londres); septiembre 23, 1967. 
Ejército vio nacer una nueva y amarga campaña de prensa dirigida contra Lo Jui-ch'ing y P'eng Teh-húai, ambos descritos como agentes de Liu Shao-ch'i, y contra sus cómplices entre las fuerzas armadas. Todos fueron acusados de haber intentado sustituir la línea proletaria por la línea burguesa militar, como un medio de facilitar el camino para la restauración capitalista. Estos cargos, junto a críticas anteriores hechas a Chu Teh, Ho Lung y otros líderes del EPL, nos llevan a la necesidad de reconsiderar nuestras primeras conclusiones respecto a la estabilidad y lealtad básica de la jefatura del EPL. Si acaso estos cargos hubieran de creerse, entonces, lejos de ser estable o leal, el EPL en el transcurso de largos años habría sido la sede de un grupo conspiratorio anti-Mao, profundamente hostil hacia el sistema de "la política en comando". Pero tales cargos no resisten un examen más detallado; por lo menos, en la forma exagerada que revistieron. Tal examen sugiere, por el contrario, que no existió oposición unificada alguna anti-Mao dentro del ÉpL del tipo ahora descrito; que los distintos líderes del EPL que actualmente eran censurados cayeron en desgracia ante los maoistas en diferentes ocasiones, por motivos diferentes y en distintos grados; y que, en la mayoría de los casos, su oposición fue una consecuencia y no un antecedente de la Revolución Cultural.

\section{Lo Jui-ch'ing}

En un sentido cronológıcu, el caso de Lo Jui-ch'ing es único. El fue expuesto como un supuesto revisionista contrarrevolucionario "en la víspera de la gran revolución cultural proletaria", y había sido ya censurado y tal vez hasta expulsado en noviembre o diciembre de 1965, mucho antes que cualquier otro líder prominente del partido. o el ejército hubiese sido atacado ${ }^{43}$. La nueva dialéctica buscó presentar a Lo como un cómplice de P'eng Teh-huai, que había continuado con la oposición de P'eng hacia la línea maoísta después de la destitución de este último en 1959. Dado que fue Lo quien reemplazó al Jefe de Estado Mayor de P'eng, Huang K'o-ch'eng, en aquella época, y en vista de que los documentos Kung-tso T'ung-hsun de 1961 muestran que Lo era ardientemente maoista en su actitud hacia los asuntos militares, es muy difícil aceptar la acusación. Sin embargo, es posible que

LarcP, editorial, julio 31, 1967 (La versión de Peking Review, agosto 4, 1967, ha sido resumida y moderada. Traducción completa cn $\boldsymbol{F g}$ 2532). En diciembre de 1965 è Buró Sud-Oeste del Partido llamó a una conferencia "desenmascarando y censurando a un 'carrerista' contrarrevolucionario del Ejército que intentó usurpar el poder del ejército y del partido (o sea. Lo Jui-ch'ing)", Radio Kunming, julio 19, 1967 (FE 2527). 
ya en 1964-65 Lo haya sentido que la politización del EPL estaba siendo llevada hasta extremos extravagantes y que sus responsabilidades como Jefe del Estado Mayor le impelían a urgir un mayor hincapié en la técnica y adiestramiento militar. Como se sugiere más arriba, fue el grado más bien que el principio de politización lo que comenzó a cạusar desaliento en el interior del EPL en esta misma época, y sería muy natural que Lo reflejase el punto de vista de sus subordinados.

Actualmente se cita a Lo de haber sostenido que "la política no debe ser realzada en forma aislada" y de haber declarado que "la política es hueca, me lo temo, si nuestro trabajo político resulta ser bueno cuando al mismo tiempo el resto del trabajo no es bueno y se derrumba" 14 . Uno de los mayores cargos en su "contra se refiere a su patrocinio durante 1964 de un concurso nacional de destreza militar; concurso que posteriormente fue criticado por Lin Piao como contrario al espíritu de "la política en comando"45. Se dice también que Lo se opuso a la expansión de la milicia, y se insinúa asimismo que fue contrario a la abolición de los rangos en 1965.

He discutido anteriormente en este mismo capítulo que el desacuerdo en torno al Vietnam puede haber producido la expulsión de Lo. Aunque los carǵos en su contra no mencionan Vietnam (y en verdad el tema no se tocó durante nïnguna de las polémicas de la Revolución Cultural), el hecho de que Lo hubiese abógado en 1964:65 por una mayor intensificación en la preparación militar, con toda seguridad debe ser considerado dentro del contexto de la guerra de Vietnam. Es interesante notar que Lo, lo mismo que P'eng Teh-huai, es acusado de haber "mantenịdo relaciones ilícitas con paises extranjeros", lo que podría dar a entender alguna forma de contacto con la Unión Soviética respecto al problema de Vietnam ${ }^{46}$. Otra parte de la acusación indica que Lo abogó por la estrategia de "defensa pasiva", o sea, defender China en las fronteras contra la invasión, en lugar de la estrategia maoísta de defensa en profundidad, por medio de la cual al enemigo se le permite invadir con la esperanza de que será devorado y rodeado por las fuerzas armadas y la milicia una vez que se encuentre fuertemente comprometido ya en territorio chino ${ }^{47}$. Aunque esto se describe como "defensa pasiva", podría más precisamente ser descrito como "defensa activa", del mismo tipo defendido por Lo durante sus dos discursos principales, refiriéndose a Vietnam, en 1965.

"Hunglienchung, "Decididamente elijan el camino de colocar' a la politica en la delantera", CPCP, agosto 30, 1967 (FR 2557).

15NGNA, agosto 25, 1967 (FE 2565).

"Hung Ch'i, editorial, No 12, 1967 (Pekin Revictu, agosto 4, 1967).

"NaNA, septiembre 16, 1967 (FE 2573). 
Aurque P'eng Teh-huai había sido destituido seis años antes que comenzase la Revolución Cultural, en cierto sentido está conectado con ésta. Los cargos que ahora se publican sugieren que la destitución de P'eng no fue nada popular en su época. Muchas personas vieron en él una víctima propiciatoria sacrificada en aras del fracaso del Gran Salto Adelante, contra el cual, por lo demás, había protestado durante la Reunión Plenaria de Lushan. El veredicto del Pleno sobre P'eng, de que era el jefe de una camarilla antipartido, y que tanto P'eng como Huang K'o-ch'eng habían tomado parte en la conspiración de Kao Kang en 1953, no parece haber teniclo amplia aceptación*8. Liu Shao-ch'i mismo es acusado de haber intentado cambiär la decisión sobre P'eng Teh-huai, y el principal cargo contra Wu Han y sus colegas escritores (hacia quienes fue dirigida originalmente la Revolución Cultural) fue también su supuesta defensa de P'eng por medio de veladas alusiones literarias ${ }^{40}$. La resolución del Pleno de Lushan en contra de P'eng no fue definitiva, lo que también sugiere falta de unanimidad. A P'eng y sus compañeros les fue permitido mantener su posición como miembros del Comité Central o del Departamento Político, para así lograr "ver cómo se comportarían en el futuro"50. En 1962, se dice que P'eng redactó un documento de 80.000 palabras, con el fin de revocar la clecisión en su contra ${ }^{51}$, y parece haberse mantenido libre hasta diciembre de 1966, fecha en que fue informado su arresto52. Yen Hung-yen, primer secretario del comité del partido en Yunnan, hasta el momento de sus críticas hechas a la Revolución Cultural y su posterior suicidio, es citado como autor de esta declaración: "P'eng Teh-huai dijo que las condiciones no estaban maduras y por esto se le fichó como adicto a la doctrina de considerar únicamente las condiciones. Ahora parece ser que él estaba en la razón"অis. La opiniọ́n de Yen puede haber sido ampliamente compartida, especialmente después de 1962, cuando el fracaso del Gran Salto Adelante había ya justificado muchas de las primeras'objeciones de P'eng.

\footnotetext{
4s"Resolución de la Octava Scsión Plenaria del Octavo Comité Central del pcc respecto al bando. anti-Partido encabezado por Peng Teh-huai" (extractos), agosto 16, 1959, Peking Review, agosto 18, 1967.

dor'Peng Teh-huai y su jefe oculto no pueden evadir la responsabilidad por sus crimenes"; Diario del Pueblo, editorial, agosto 16, 1967 (Peking Revietv, agosto 25, 1967). over nota 48.

"'Con poder de sobra debemos perseguir al tambaleante enemigo", CFcr, . editorial, agosto 16, 1967 (PE 2546).

Sadio Moscú, enero 2, 1967, (FE 2357).

Radio Kunming, agosto 3, 1967, (FE 2540).
} 
Durante 1966, después de la expulsión de Lo Jui-ch'ing, no existían in.. dicios de que el EPL aún amparase a algún miembro de la "negra" banda antipartido. Fue solamente a fines de ese año que varios líderes del escalón secundario, quienes hasta entonces habían seguido la corriente de la Revolución Cultural, fueron clenunciados y destituidos. Fueron ellos víctimas, junto a otros líderes del partido más prominientes (siendo el más notorio $\mathrm{T}^{\prime}$ en $\mathrm{Chu}$, quien había sucedido a $\mathrm{Lu}$ Ting-yi como Director del Departamento de Propaganda del Partido), de la última intensificación de la Revolución Cultural; intensificación que se extendió hasta las filas del hasta entonces inmune EPL. En la medida en que en verdad ellos representaron un grupo de oposición organizado, fue probablemente más bien en virtud de su relación con $T^{\prime}$ ao Cliu que por conexión alguna con un centro de poder militar. Su miembro más prominente fue Hsiao Wang-t'ung, acusaclo de ser un protegiclo de T'ao Chu, y también equivalente de T'ao como Ministro de Cultura Interino sucesor de Lu Ting-yi ${ }^{54}$. Liu Chilh-chien y Liang Pi-yeh, los dos subdirectores del Departamento General de Política removidos en esos mismos días, fueron ambos acusados de haber tomado la parte de $\mathrm{T}^{\mathrm{a}}$ ao $\mathrm{Chu}^{\mathrm{55}}$. Otras víctimas fueron Hsiao Hsiang-jung, jefe de la oficina administrativa del Ministerio de Defensa Nacional, y Wang Jen-chung, comisario político de la guarnición de Wuhan. También los dos fueron acusados de

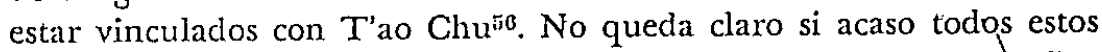
hombres habían realmente estado estrechamente asociados con $T$ 'ao Chu en el pasado (es más probable en los casos de Hsiao Hsiang-jung y de Liang $\mathrm{Pi}$-yeh). El factor importante fue el hecho de que su oposición ante la intensificación de la Revolución Cultural coincidió con la de T'ao Chu en ese momento.

\section{LOS MARISCALES MILITARES}

En los primeros meses de 1967 nadie estaba a salvo de los ataques de los Guardias Rojos y de los rebeldes revolucionarios. Cada Mariscal del EPL aún en funciones (o más correctamente "ex Mariscal" desde la abolición de los rangos), sufrió las críticas en uno u otro momento,

aVer el ataque a Hsiao Wang-t'ung en "Una línea negra", Pekín: Mao Tse-tung Chu-i Chan-tou Pao, No 2, febrero 23, 1967, (scmp 3903).

w5En 1954 Liang Pi-yeh era subjele del Depto. Político de la Región Militar Central-Sur, del cual T'ao Chu cra jefe.

coHsiao Hsiang-jung había sido comisario político del Buró de Seguridad Pública de Kiveichow en 1950 . 
'según las informaciones. Pero cuando la confusión comenzó a disiparse, solamente uno, Ho Lung, habia desaparecido. Chu Teh, aunque ferozmente atacado, hizo su aparición sobre el estrado del Día de Mayo.

Aparte de sus tempranos delitos, que se remontaban tan atrás como para incluir el Levantamiento de Nanchang, el cargo principal en contra de Ho Lung se refería a su supuesto apoyo del grupo de T'eng Chen clurante los primeros meses de la Revolución Cultural. Se dijo que había ayudado a P'eng Chen en la confección de un informe del Comité Central sobre la Revolución Cultural de febrero de 1966; informe que trataba de debilitar los ataques de la Revolución dirigidos contra los protegidos de P'eng dentro de la administración de Pekín ${ }^{57}$. Ho Lung también fue acusado de haber conspirado contra Mao, junto a otros lícleres que incluian a Liu Shao-ch'i, durante su ausencia de Pel.ín que se prolongó por cincuenta días, àntes del 11 \% Pleno de agosto 1966" . El verdadero significado del "Informe de Febrero" y del "Complot de Julio" queda aún por descifrarse. Puede ser que Ho Lung haya teniclo algún papel en ellos; sin embargo es muy sorprendente que en tal caso él haya figurado prominentemente durante las asambleas de Guardias Rojos en el otoño de 1966 y que haya aparecido en una manifestación por Vietnam en una fecha tan tardía como el 18 de diciembre. Parece muy probable que Ho Lung, como muchos otros altos lideres, solamente haya abandonado la Revolución Cultural cuando este movimiento se aceleró a fines del año, cualesquiera hayan siclo sus reservas anteriores respecto a ésta ${ }^{59}$.

Los ataques sobre Chu Teh fueron bastante desganados, tal vez debido a su gran reputación en el pueblo. Lin Piao le describio, según dicen, como "un comandante en jefe no capacitado"; en otras partes se le atacó como vano y ambicioso, basándose en una biografía encomiástica de sí mismo que Chu Teh hizo escribir en 193960. Aparentemente todos los líderes chinos fueron sometidos a esta especie de crí-

\footnotetext{
87Una circular del Comité Central condenatoria del informe de P'eng Chen, fechada mayo 16 , 1966, Sue publicada un año más tarde, Peking Revietw, mayo 19, 1967. También corría el rumor de que un golpe militar habia sido planeado en febrero, pero de acuerdo con Teng Hsiao-p'ing no cxistió tal incidente, "Discurso del Camarada Teng Hsiao-p'ing el 2 de agosto en la Universidad del Pueblo", Consulado General de usA, Hong-Kong, Current Background, (св) 819.

* Una versión de las circunstancias de los movimientos y contramovimientos militares en julio 1966, que es imposible verificar, fue publicada en el diario yugoslavo Polilika y resumida en Alexandra Close, "The Chinese army's task", Far Easlern Economic Review, enero $12,1967$.

${ }^{60}$ Ver crítica a Ho Lung en "Inmensos crímenes de Ho Lung, elemento antipartido y usurpador del ejército (1)", T'i-yu Ghan-hsien, enero 28, 1967 (scmp 3912).

oo"Confesión de Chu Teh, hombre de desmesurada ambición para usurpar el partido y el ejército, descubriendo la gran conspiración de la Biogra/la del General Chu Teh", Hsin Pei-ta, No 39, febrero 16, 1967 (св 822).
} 
ticas superficiales provenientes de una u otra unidad de Guardias Rojos; o sea, que esta crítica no debe considerarse de gran importancia, salvo en la medida en que sirve como indicador del perdiclo respeto hacia la jefatura tanto del partido como del ejército, y de la extensión alcanzada por cierta libertad de expresión entre los Guarclias Rojos ${ }^{01}$.

Por agosto de 1967, varios otros oficiales del EPL habian sido cen* surados y expulsados, algunos acusados de asociación con 'T'ao Chu u Ho Lung; otros, por negarse a intervenir en favor cle la parte correcta con las unidades militares bajo su control, o por tomar particlo por la oposición. Algunos secretarios gencriles provinciàles o regionales de mayor importancia, quienes eran comisarios políticos de las unidades militares dentro de su jurisclicción, fueron destituiclos -incluyendo a $W^{\prime} u$ Lann-lu y a I.i Cihing-chuan un común denominaclor entre todats estas autoriclacles, o caracterizarles como miembros de algún grupo militar iclentilicable. En el caso de lọs primeros secretarios, su posición de partido antes que su posición militar fue probablemente el lactor mís decisivo de su destitución. Uno podría concluir que, a mediaclos de 1967 , la organización intema clel EPL habia siclo tan seriamente dañata por la Rerolución Cultural como lo habian sido liss del partido y cl gobierno; estal desorganización interna; sin combargo, no implicaría clr absoluto que una oposición unificada proveniente descle el spt. hubiese ya surgido.

\section{CONCLISIONES}

La Revolución Ciultural no solamente lanzó a la totalidacl de la República China en la confusión, sino que aclemís produjo similar clesorientación en el campo de la sinología contemporánea. Esta conmoción fue seguramente muy saluclable para la sinología, si no tanto para los chinos. No obstante, habrá cle transcurrir un tiempo antes de que sus efectos logren ser asimilaclos. Consideremos que es ya sumamente difícil el problema de intentar comprender la verdadera naturaleza y conteniclo de la Revolución. Cultural misma, sin el agregaclo de la reevaluación cle nuestra interpretación de la época preRevolución Cultural a la luz cle las recientes revelaciones.

En cuanto al EPL, de inmediato se formulan las siguientes tres interrogantes especificas: Primeramente, clas revelaciones recientes sugieren acaso un grado muchísimo mayor de oposición militar hacia

${ }^{1}{ }^{2}$ 'iu Hui-tso, Hsiao Ching-kuang, Hsu Hsiang-ch'ien y Yeh Chien-ying, entre otros, fueron criticados en los primeros meses de 1967 , pero ann eran visibles durante las celebraciones del Día de Mayo o del Dia del Ejército (agosto 19).

asprimeros Secretarios del Partido y Primeros Comisarios Políticos de las regiones de Mongolia Interior $y$ del Sud-Ocste (Chengtu), respectivamente. 
el partido o hacia Mao durante el pasado que el calculado anteriormente? En segundo lugar, tel papel ambiguo jugado por el EPL durante la Revolución Cultural lanza acaso también dudas sobre las conclusiones anteriores respecto a su homogeneidad y lealtad esencial hacia las autoridades centrales? $Y$ en tercer lugar, ¿deberá su actuación durante la Revolución Cultural ser interpretada básicamente como una oposición, un apoyo, o ninguna de estas dos cosas? Algunas respuestas tentativas se sugieren ya durante este capítulo final y serán ahora resumidas a manera de conclusión: .

1. Las abrumadoras acusaciones retrospectivas hechas a tantos lideres militares, en las cuales se les presenta como conscientemente contrarrevolucionarios y se les sindica de pertenecęr a un grupo antimaoísta, no se sostienen ni siquiera por la evidencia que estas mismas tratan de proporcionar. Tal como se ha demostrado en la sección de más arriba, estos jefes han caido bajo el ataque crítico en diferentes ocasiones y en diferentes contextos. Traspasa los límites de la creclibilidad el juzgarles como elementos antipartido que han estado escondidos dentro del ejército y partido desde los primeros días de la revolución. Sin embargo, se puede creer en que efectivamente éstos han siclo los cargos formulados ahora en su contra. Para lograr desalojar líderes veteranos que aún puede que gocen de considerable apoyo popular, es neccsario nó sólo desacreditarlos individualmente, sino aclemás caracterizarles clentro de un grupo conspirante organizado y amenazante. La táctica es muy conocida y en ese sentido (aunque en ningún otro) existe aquí una semejanza con los juicios de traicición de Stalin.

A pesar de todo esto, es muy posible que algunas semillas de verdad hayan subsisticlo entre los cargos contra estos y otros líderes. Sería bastante ingenuo suponer que las jefaturas del partido y del ejército hubiesen estado siempre exentas de diferencias de opinión en el pasado. En el momento, tales discrepancias fueron contenidas con todo éxito, en el espíritu de la "democracia dentro del partido", ya sea por medio de transacciones o clecisiones mayoritarias. En algunos casos, los autores de decisiones que más tarde resultaren ser erradas, podrían ser censurados dentro del partido, pero sin ser expulsados ni públicamente criticados. Así, decisiones que aparecían como unánimes habrían sido precedidas, e incluso a veces seguidas -muy lícitamente por lo demás- por debates y controversias genuinas. Sólo muy ocasionalmente se divulgaron estos debates como en el caso de Kao Kang o de P'eng Teh-huai, hasta ser materia de pública discusión y condena. Unicamente ahora los posesores de posiciones minoritarias o los abogados de políticas erradas (según la pauta de Mao) son com- 
siderados como antiparticlo y como contrarrevolucionarios en gran escala. En el caso del EpL, la controversia en el pasado siempre se había centrado sobre las perennes interrogantes cle las prioridades políticas y militares. Si se toman en cuenta sus antecedentes, es imposible creer que Lo Jui-ch'ing, o Ho Lung, e incluso P'eng Telh-huai, se hayan jamás opuesto al principio del control del partido e indoctrinación política. Pero por distintos motivos y en distintos momentos en el tiempo, cada uno de ellos se encontró incapaz de reconciliar ambas prioridades $y$, en consecuencia, se sintió obligado a ingresar en la oposición. Este mismo dilema fue compartido y, sin ducla alguna, es aún comparticlo por muchos líderes del Ept menos destacaclos, cuyos nombres ignoramos.

2. Durante la Revolución Cultural el Epr ha mostraclo sintomas de desunión interna $y$, en algunas oportunidades, cle oposición al lats autoridades centrales. Esto no invalicla en absoluto, sin embargo, nuestras conclusiones precedentes respecto a su homogeneidlad y lealtad bísica-antes de la Rerolución Cultumal. La contradicción es más bien aparente que real $y$ se explica por el moclo en que la Revolución Cultural destruyó completamente los tradicionales puntos de relerencia dentro de cuyos límites la unidacl y lealtad del rirL podia ser garantizada. La lealtad del ejército dependía de lil existencia de una jefatura central unificada, que transmitiese la política que se clebía seguir con características más o menos iclénticas $y^{\prime}$ cn forma simultáneat a través cle todo el instrumental organizativo militar, particlario y gubernamental. Todo el proceso cle politización clel Ex'L descle 1960) se había iclentilicado con la firme lealtad hacia la ecuación polítical "Mao = el Partido". El pensimiento cle Mao Tse-tung constituía el respaldo ideológico para la autoridad cle los secretarios clel partido, quienes, a distintos niveles, hacian cumplir las instrucciones centrales por medio del sistema de control político.

A medicla que progresaba la Revolución Cultural, se tornó cadat vez. más difícil continuar con la ecuación cle Mao y el particlo. Descle fines de 1966, dicha ecuación en muchos Iugares de Cinina había sido totalmente destruida, pudiendo leérsela ahora "Mio $\neq$ el Partido". O asíaparecía a los ojos del comandante militar que se encontrara en la engorrosa situación de verse forzaclo a tomar parte entre los revolucionarios rebeldes y las autoriclades locales del particlo (que eran a su vez sus superiores políticos) en cl momento que los últimos eran atacados. $Y$ lo que era aún peor, tampoco podía ahora confiar en que recibiría instrucciones superiores para solucionar la discorclia. La naturaleza misma de la Revolución Cultural, con una especie cle democracia primitiva floreciendo a nivel local entre los rebeldes revolu- 
cionarios, conjuntamente con las rivalidades de diferentes focos de autoridad a nivel central, impiclieron que tales instrucciones fuesen enviaclas con claridad suficiente como para lograr ser consideradas verdaderos mandatos.

La unidad interna del EPL se condicionó de similar manera. En la medida en que el control del particlo era absolutamente penetrante y monolítico, no existía necesidad alguna de utilizar el sistema tradicional cle controles y contrapesos con el que siempre se intentaba evitar (sin éxito a veces) que los ejércitos precomunistas de China desafiasen las autoridades centrales. De ahí entonces la facilidad con que se disolvió la estructura nacional de control militar del EPL durante los primeros años de la República Popular, y el fenómeno - notable para muchos vbscralores extemos- de autoridades y unidades a las que se permilia mantener sus posiciones, muy a menudo en su propia provincia de origen, por años de años.

Con la desintcgración de la autoridad central de Pekín durante la Revolución Ciultural, y también de sus cadenas de comando vertical, la única barricala contra el regionalismo y separatismo militar habín caíclo. Es tal re un síntoma de la fuerza más bien que de la clebiliditd del sistemia cle control del partido previo a la Revolución Cultural, que los antiguos hábitos cle obediencia y no intervención en la política hayan persistido dentro del EPL después de que los reales controles materiales habían sido retirados. El EPL no intentó apoderarse del país en. favor de Mao en 1966, como tan fácilmente podría haberlo hecho. Talupoco se tornó en una unificada oposición a Mao en 1967, como también podria haber actuado. Dondequiera fue posible, se manturo inactivo, procurando evitar cualquier compromiso con pairte alguna, salvo al verse forzado a lit acción para lograr resguarclar lis ley y seguriclad pública o su propia supervivencia.

3. Hasta lines de 1966, el Epro había sobrevivido a la Revolución Cultural con mayor facilidad que ningún otro sector de la sociedad china. Sin lugar a cluclas, existieron discordia y tensión entre sus filas, como lo inclicaría la expulsión de Lo Jui-ching en vísperas de la Revolución Cultural; pero hasta cierto punto esto se compensó con el incrementaclo prestigio ahora adquirido. La lealtad hacia Mao der tipo exagerado ahora exigida por la Revolución Cultural fue muy probablemente, en todo caso, más fuerte dentro del EPL que fuera de éste, como resultado de sus años de preparación como un modelo político maoísta. Así el EPL pudo ser considerado como fundamentalmente pro-Mao, pero, eso sí, planteando ciertas condiciones: (1), que la Revolución Cultural no penetrase en sus propias filas; (2), que la brecha abierta entre Mao y el Partido no se ensanchase incontrolablemente, 
y (3), que no fuese el EPL llamado a.intervenir físicamente. Un acuerdo tácito parece haber existido en el otoño de 1966 en el sentido de que estas condiciones serían respetadas. Según parece, T'ao Chu y otros líderes del partido también apoyaron a Mao bajo condiciones similares, incluyéndose en ellas la exención de la agricultura e industria de la Revolución Cultural y tal vez además ciertas salvaguardias para la burocracia del partido.

Si acaso fue siempre la intención de Mao ir muy lejos con la Revolución Cultural, o si ésta sencillamente adquirió tal ímpetu que su precipitacla escalada no pudo ser frenacla, ya en 1967 todas estas limitaciones habían sido barridas, junto a unos pocos lideres del partido y del ejército que hasta el momento habian logrado mantener su posición. El EPL fue llamado a intervenir en circunstancias en que el acto de intervención muy probablemente le enajenaria el apoyo popular, al propio tiempo que una no intervención igualmente disminuiria su autoridad. Lá gran mayoría de los jefes del EpL actuó con los menores riesgos posibles; intentando llegar a entendimientos con las fuerzas políticas locales, a la ve\% que absteniéndose de desafiar abiertamente la jefatura maoísta en Pekín. Pero, al promediar el año, el incidente de Wuhan demostró que un compromiso de esa naturaleza era cada vez más difícil de sostener. En septiembre y octubre pareció que Mao hubiese, por lo menos momentáneamente, llegaclo a la misma conclusión y existieron tentativas bajo su mando de estrechar filas y restablecer alguna forma viable de cooperación activa entre el ejército, el particlo y las fuerzas revolucionarias.

La contradicción aparente entre los papeles del EPL en 1966 y en 1967, se explicaría en consecuencia por las circunstancias tan enormemente diferentes existentes cn estos dos años, en medio de las cuales el ejército, junto al resto de la sociedad china, se encontró operando. Su papel en el porvenir dependerá igualmente del curso futuro que siga la Revolución Cultural. Si acaso ésta ha alcanzado su etapa final, aún será posible reparar los lazos rotos entre los máoístas y la burocracia del partido, por un laclo; y entre estos dos y el EPL, por el otro. Puede que aún perdure un residuo de lealtad dentro del EPL que permita que tal proyecto sea factible. Empero, la calidoscópica confusión reinante clurante dos años de Revolución Cultural ha sometido a la bien engranada, unidad de la jefatura del EPL a un duro esfuerzo; sin mencionar a sus relaciones con el partido y con la población civil. Puede que transcurra un largo periodo antes de que la situación vuelva a ser como antes, si en realidad algún día se logra esto. El papel del EPL en China, tan delicadamente equilibrado, construido con tanto esfuerzo y clificultad a lo largo de tantos años, ha 
sido seriamente trastornado, aunque todavía parecen existir algunos vestigios de capacidad recuperativa. Y si la Revolución Cultural, lejos de llegar a su fin, escala aún más, puede que el EPL se vea forzado por la desesperación a tomar las riendas en su mano. Pero no podemos menos que estar impresionados por el autodominio demostrado hasta el momento. Sería sumamente difícil nombrar como ejemplo a alguna otra nación en desarrollo, poseedora de un poderoso y popular ejército, donde los militares se hayan sometido a dos años de maelstrom político sin actuar por cuenta propia en nombre del restablecimiento de la tranquilidad.

Aunque el EPL no haya intervenido en favor de Mao Tse-tung tan decisivamente como éste hubiese esperado, debería Mao considerar que el medio político en que el ejército fue adiestrado durante las tres décadas anteriores -en gran parte obra del mismo Mao- ha sido la causa que por lo menos ha impedido que el Ejército Popular de Liberación se vuelque en su contra.

Scptiembre 1967 